\title{
PEMANFAATAN LIMBAH SEKAM PADI SEBAGAI ASAP CAIR
}

\section{UTILIZATION OF RICE HUSB WASTE AS LIQUID SMOKE}

\author{
Dani Hari Tunggal Prasetiyo ${ }^{1)}$, Djoko Wahyudi ${ }^{2)}$, Oki Maskur ${ }^{3)}$ \\ ${ }^{1,2,3}$ Fakultas Teknik, Universitas Panca Marga \\ ${ }^{1}$ Email: dani.hari59@gmail.com
}

\begin{abstract}
Abstrak: Limbah pertanian memiliki banyak manfaat, salah satunya adalah sekam padi. Saat ini sekam padi masih dimanfaatkan sebagai pupuk, briket dan katul, namun pemanfaatan sebagai insektisida masih jarang digunakan. Salah satu insektisida organik dapat diperoleh dari limbah sekam padi berupa asap cair. Asap cair diperoleh dengan metode pirolisis dengan cara menguraikan senyawa organik yang terdapat pada sekam padi. Tim Prodi Teknik Mesin Universitas Panca Marga (UPM) Probolinggo melakukan kegiatan pengabdian masyarakat berupa pelatihan pembuatan alat asap cair dengan bahan limbah sekam padi sebagai salah satu bentuk implementasi Tridarma Perguruan Tinggi. Sasaran kegiatan pengabdian masyarakat adalah gabungan mahasiswa dari beberapa program studi di lingkungan UPM Probolinggo. Hasil yang diperoleh dari kegiatan ini adalah peserta dapat membuat alat, memproduksi asap cair dan memberikan contoh penggunaan asap cair di lingkungannya khususnya kepada petani.
\end{abstract}

Kata Kunci: Asap cair, Limbah sekam padi, Pirolisis, Insektisida

Abstract: Agricultural waste has many benefits, one of which is rice husk. Currently, rice husk is still used as fertilizer, briquettes and katul, but its use as an insecticide is still rarely used. One of the organic insecticides can be obtained from rice husk waste in the form of liquid smoke. Liquid smoke is obtained by the pyrolysis method by decomposing organic compounds contained in rice husks. The Mechanical Engineering Study Program Team of the Panca Marga University (UPM) Probolinggo carried out community service in the form of training on making liquid smoke tools with rice husk waste as a form of implementing the Tridarma of Higher Education. The target of this community service activity is a combination of students from several study programs within UPM Probolinggo. The results obtained from this activity are that participants can make tools, produce liquid smoke and provide examples of use in the environment, especially to farmers.

Keywords: Liquid smoke, Rice husk waste, Pyrolysis, Insecticide.

\section{PENDAHULUAN}

Indonesia merupakan negara agraris dengan mayoritas penduduknya berprofesi sebagai petani. Produksi padi Indonesia pada tahun 2014 sebesar 70,85 
juta ton gabah kering giling (GKG) (Ishaq dkk., 2017). Gabah menghasilkan limbah kering yaitu sekam. Sekam dihasilkan dari kulit terluar gabah kering. Berat sekam padi yang dihasilkan adalah 22\% dari berat gabah kering giling (Dewi dkk., 2020). Saat ini sekam padi masih dimanfaatkan sebagai pupuk, briket dan katul, namun masih jarang dimanfaatkan sebagai insektisida (Sari dkk., 2017).

Salah satu insektisida organik dapat diperoleh dari limbah sekam padi berupa produk asap cair. Asap cair adalah hasil kondensasi dari uap hasil pembakaran secara langsung atau tidak langsung dari bahan-bahan yang banyak mengandung karbon serta senyawa-senyawa lain seperti selulosa, hemiselulosa, dan lignin (Istiqomah dan Kusumawati, 2020). Asap cair sekam padi memiliki kandungan fenol 5,13\%, karbonil 13,28\%,dan asam 11,39\% (Jaya dkk., 2016). Asap cair diperoleh dengan metode pirolisis dengan cara menguraikan senyawa organik yang terdapat pada sekam padi. Asap cair sekam padi memiliki banyak manfaat dalam dunia pertanian. Manfaat asap cair sekam padi antara lain sebagai pengusir hama, pengusir lalat, penghilang bau tak sedap dan pupuk. Saat ini Asap cair sekam padi masih jarang digunakan secara optimal oleh masyarakat. Hal ini dikarenakan masih kurangnya pengetahuan masyarakat tentang alat yang digunakan dan cara pembuatannya. Oleh karena itu diperlukan pelatihan pembuatan alat untuk memproduksi asap cair dari sekam padi sehingga masyarakat dapat membuat, menggunakan dan mengimplementasikan produk asap cair. Produk dan alat asap cair sekam padi sangat bermanfaat bagi masyarakat di Kab. Probolinggo. Hal ini dikarenakan mata pencarian masyarakat didominasi disektor pertanian.

Oleh karena itu, sebagai salah satu bentuk implementasi Tridarma Perguruan Tinggi, tim Teknik Mesin Universitas Panca Marga Probolinggo (UPM) Probolinggo melakukan kegiatan pengabdian berupa pelatihan pembuatan alat asap cair dengan bahan limbah sekam padi. Sasaran kegiatan adalah mahasiswa dari beberapa program studi di lingkungan UPM Probolinggo. Mahasiswa menjadi sasaran kegiatan dikarenakan mahasiswa memiliki semangat yang tinggi untuk terus berinovasi dan berkarya. Dengan harapan setelah mengikuti pelatihan peserta dapat membuat alat, memproduksi asap cair dan 
INTEGRITAS : Jurnal Pengabdian

Vol 5 No 2 Desember 2021

ISSN 2580 - 7978 (cetak) ISSN 2615 - 0794 (online)

memberikan contoh penggunaan asap cair di lingkungannya kususnya kepada petani. Selain itu, aspek lingkungan, teknologi pirolisis yang menghasilkan asap cair, dapat merubah biomassa menjadi produk yang ramah lingkungan, sehingga dapat menurunkan tingkat $\mathrm{CO}_{2}$ di atmosfer dan mengurangi volume biomassa (Iskandar \& Kartika Fitri, 2018).

\section{METODE}

Kegiatan pengabdian masyarakat dilakukan dengan memberikan pelatihan pembuatan alat asap cair dengan bahan baku dari limbah sekam padi. Sasaran peserta adalah kelompok mahasiswa dari berbagai program studi di lingkungan UPM Probolinggo. Metode pelaksanaan pengabdian masyarakat terdiri dari beberapa tahapan antara lain tahap perencanaan dan tahap pelaksanaan. Pelaksanaan acara pengabdian masyarakat dilaksanakan oleh Prodi Teknik Mesin, UPM Probolinggo dengan tahapan sebagai berikut:

\section{Tahap Perencanaan}

Tahap perencanaan diisi dengan kegiatan pembekalan materi dan study literatur. Kegiatan diikuti oleh peserta dan diisi oleh pemateri. Pemateri terdiri dari tiga orang, yaitu Dani Hari Tunggal Prasetiyo, Djoko Wahyudi, dan Oki Maskur. Pelaksanaan kegiatan di jadwalkan sebagai berikut:
a. Waktu : 24 Maret 2021
b. Tempat : Lab. Motor Bakar Teknik Mesin UPM Probolinggo
c. Jumlah : 20 peserta.

2. Tahap Pelaksanaan

Pelaksanaan kegiatan dilakukan oleh peserta sedangkan pemateri memonitor jalannya kegiatan agar sesuai dengan hasil yang diharapkan. Pelaksanaan kegiatan di jadwalkan sebagai berikut:
a. Waktu : 25 dan 26 Maret 2021
b. Tempat : Lab. Proses Produksi Teknik Mesin UPM Probolinggo
c. Jumlah : 20 peserta. 


\section{HASIL DAN PEMBAHASAN}

Pada tanggal 24 maret 2021 Kegiatan diawali dengan pembekalan materi dan study literatur, kemudian dilanjutkan dengan presentasi ulang oleh seluruh peserta. Presentasi ulang dilakukan untuk mengukur pemahaman peserta terhadap materi yang telah disampaikan. Hal ini dilakukan agar pelaksanaan pembuatan alat dan produksi asap cair tidak terkendala dan meminimalisir resiko. Komunikasi dilakukan dua arah, sehingga peserta antusias saat mengikuti acara. Gambar acara tahap perencanaan dapat dilihat pada Gambar 1.

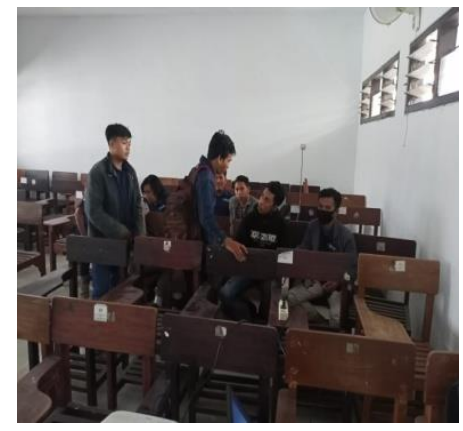

(a)

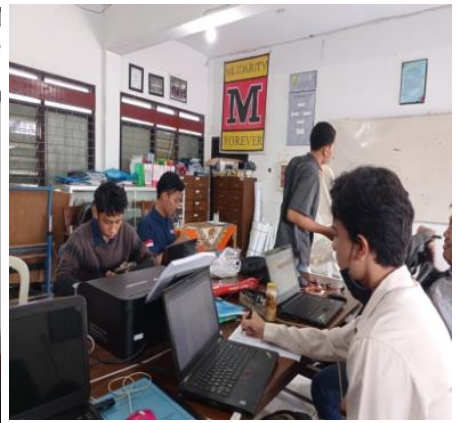

(b)

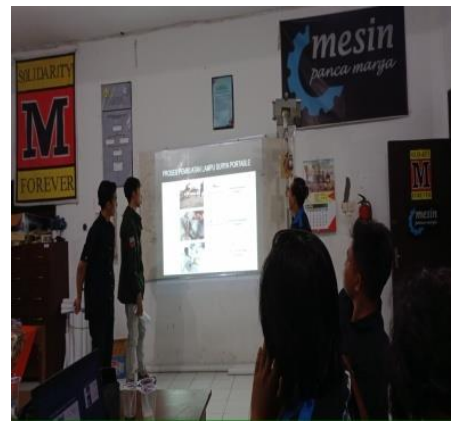

(c)

Gambar 1. Pelaksanaan Acara Perencanaan (a) Pemaparan Teori (b) Diskusi dan Persiapan Presentasi (c) Presentasi Oleh Peserta

Pada tanggal 25 maret 2021, kegiatan diisi dengan kegiatan mempersiapkan alat dan bahan untuk membuat alat asap cair. Adapun beberapa alat dan bahan yang digunakan dapat dilihat pada Tabel 1 dan 2 sebagai berikut:

Tabel 1. Rincian Bahan Untuk Membuat Alat Asap Cair Dari Limbah Sekam Padi

\begin{tabular}{cll}
\hline No & \multicolumn{1}{c}{ Nama Barang } & Jumlah \\
\hline 1 & Pipa stainless steel 1/4” & 1 Unit \\
2 & Pipa stainless steel 3" & 1 Unit \\
3 & Fitting one way & 1 Buah \\
4 & Pipa PVC 1/4" & 1 Unit \\
5 & Tong bekas & 1 Buah \\
6 & Kompor oli bekas & 1 Unit \\
7 & Siku 4x4 ks & 1 Unit \\
8 & Penyaring air & 2 Buah \\
9 & Lem besi & 1 Buah \\
10 & Pompa air & 1 Unit \\
11 & Selang & 2 Meter \\
12 & Gelas ukur & 1 Buah \\
13 & Las listrik & 1 Unit \\
14 & Baut dan mur & 6 Biji \\
\hline
\end{tabular}


INTEGRITAS : Jurnal Pengabdian

Vol 5 No 2 Desember 2021

ISSN 2580 - 7978 (cetak) ISSN 2615 - 0794 (online)

Tabel 2. Rincian Bahan Yang Untuk Membuat Asap Cair Dari Limbah Sekam Padi

\begin{tabular}{cllc}
\hline No & Nama Barang & Jumlah & Keterangan \\
\hline 1 & Sekam padi & $5 \mathrm{Kg}$ & $\begin{array}{c}\text { Bahan baku asap cair } \\
\text { Bahan bakar kompor / } \\
\text { pemanas reaktor }\end{array}$ \\
3 & Oli bekas & $3 \mathrm{Liter}$ & $\begin{array}{c}\text { Pemicu api pada burner } \\
\text { kompor/ pemanas }\end{array}$ \\
\hline
\end{tabular}

Kegiatan hari kedua pembuatan alat diawali dengan memotong bahan seperti besi dan pipa. Proses awal melakukan penyambungan pipa dengan tabung bekas. Tabung pertama digunakan sebagai reaktor dan tabung kedua digunakan sebagai pendingin. Kemudian dilanjutkan dengan membentuk dan menyambung potongan pipa menjadi bentuk spiral. Pipa spiral berfungsi sebagai tempat sirkulasi asap limbah sekam padi. Gambar alat asap cair dapat dilihat pada Gambar 2.

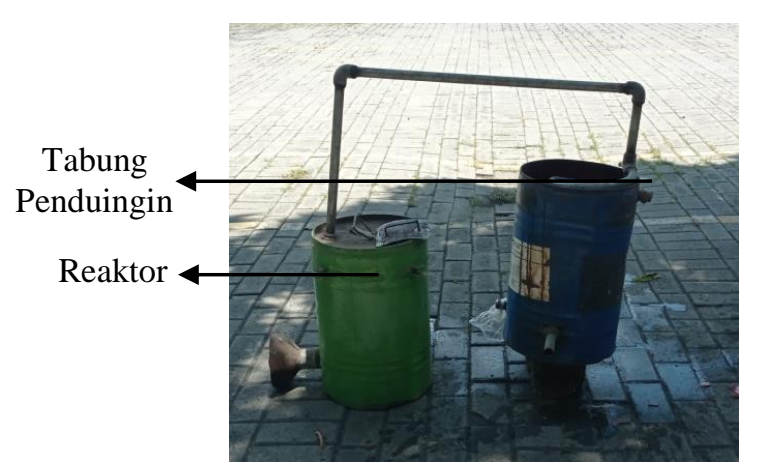

(a)

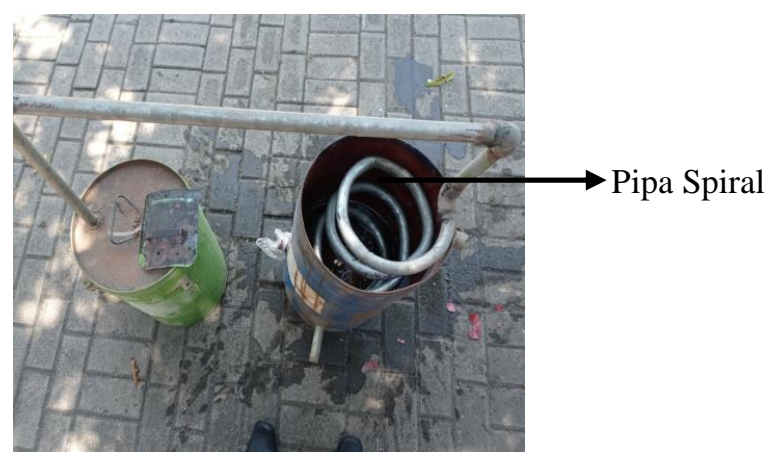

(b)

Gambar 2. (a) Alat Asap Cair (b) Bagian Pipa Spiral

Tabung reaktor berfungsi sebagai pemanas sekam padi dengan sedikit oksigen sehingga sekam padi mengalami pemecahan struktur kimia menjadi fase gas. Fase gas dari tabung reaktor dialirkan menuju pipa spiral. Hal ini bertujuan agar proses pirolisis terdistribusi lebih merata dan lebih effisien. Pipa spiral diletakkan pada tabung pendingin. Tabung pendingin diisi dengan air yang tersirkulasi dengan menggunakan pompa. Tujuan sirkulasi air agar suhu tetap stabil.

Pada hari ketiga, tanggal 26 maret 2021, kegiatan uji coba alat dan produksi asap cair. Kegiatan dibantu pemateri saat melakukan uji coba sehingga menghasilkan produk yang diharapkan. Peserta merasakan manfaat adanya praktek pembuatan alat. Proses pembuatan alat bertujuan agar peserta dapat 
membuat dan mengaplikasikan setelah selesai acara pengabdian masyarakat. Seluruh peserta diwajibkan mengikuti dan melaksanakan pembuatan alat asap cair. Peserta antusias bertanya jika terdapat kendala. Gambar proses pembuatan alat asap cair dapat dilihat pada Gambar 3.

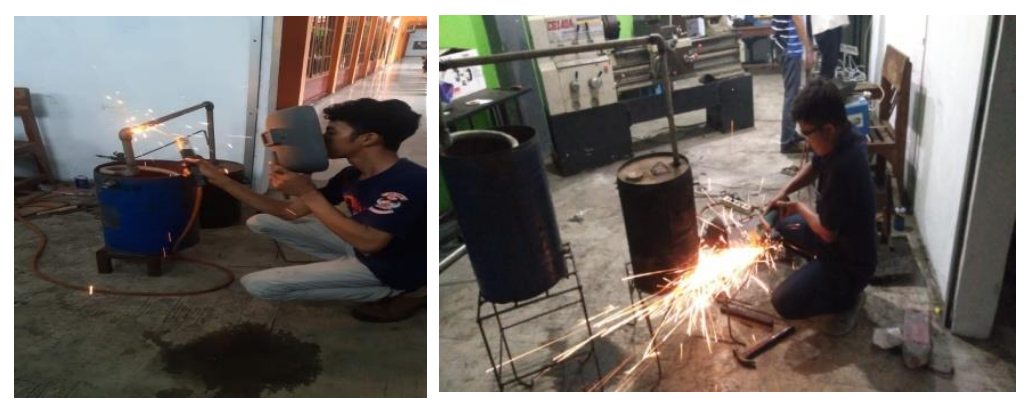

Gambar 3. Proses Pembuatan Alat Asap Cair

Setelah selesai, alat asap cair diuji coba. Pengujian alat berjalan dengan baik dan efisiensi. Hal ini dikarenakan alat yang dibuat melalui proses perencanaan yang matang serta diskusi sehingga saat terjadi masalah dapat diputuskan secara langsung. Saat, proses produksi asap cair, reaktor dipanaskan dengan menggunakan kompor berbahan bakar oli bekas. Peserta merasakan manfaat dari acara pengabdian masyarakat. Peserta menginginkan adanya program pelatihan kembali yang dilakukan oleh Prodi Teknik Mesin UPM Probolinggo dengan tema yang berbeda sehingga menambah wawasan dan pengetahuan kepada peserta. Gambar proses dan produksi asap cair dari limbah sekam padi dapat dilihat pada Gambar 4.

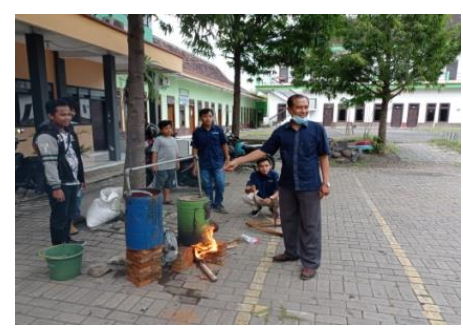

(a)

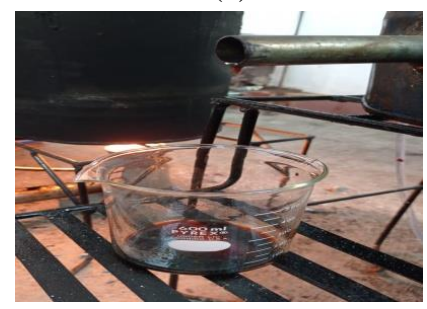

(c)

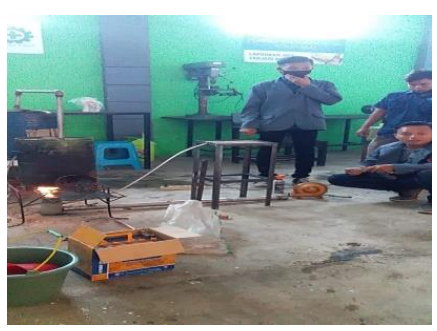

(b)



(d)

Gambar 4. (a) Uji Coba Alat (b) Proses Produksi (c) Hasil Proses Produksi (d) Produk Asap Cair 
Produk yang dihasilkan berupa asap cair. Asap cair dapat digunakan sebagai pengusir hama dan lalat. Produk Asap cair memiliki nilai ekonomis dan dampak lingkungan. Nilai ekonomis yang diperoleh adalah mengurangi biaya perawatan kususnya dalam bidang pertanian bawang dan tomat. Hal ini dikarenakan petani dapat membuat sendiri insektisida pengusir hama dari bahan baku limbah padi yang tidak terpakai. Dampak terhadap lingkungan yaitu, mengurangi penggunaan bahan kimia pada pertanian, sehingga produk pertanian aman untuk dikonsumsi. Selain itu mahasiswa sebagai agen perubahan dapat mengaplikasikan ilmu yang telah diperoleh melalui pelatihan dalam kehidupan sehari-hari.

Dari rangkaian acara pengabdian masyarakat yang telah dilaksanakan, terdapat beberapa hal yang diperoleh saat acara berlangsung antara lain sebagai berikut:

1. Meningkatkan pengetahuan tentang inovasi teknologi kususnya metode pirolisis;

2. Meningkatkan pengalaman dan pengetahuan pembuatan alat asap cair dengan memanfaatkan limbah sekam padi;

3. Meningkatkan pengetahuan tentang manfaat asap cair pada bidang pertanian;

4. Asap cair dapat dipasarkan melalui media sosial. dengan harga terjangkau untuk menambah penghasilan.

\section{KESIMPULAN}

Kegiatan pengabdian masyarakat oleh Tim Prodi Teknik Mesin UPM Probolinggo dilakukan selama tiga hari, acara diisi dengan pelaksanaan pelatihan pada hari Rabu tanggal 24 maret 2021 di laboratorium motor bakar teknik mesin UPM Probolinggo dengan isi acara pembekalan materi dan styudy literatur,. Acara pelaksanaan pada tanggal 25 dan 26 maret 2021 diisi dengan persiapan alat dan bahan kemudian pembuatan alat. Kegiatan pengabdian dengan tema pemanfaatan limbah sekam padi menjadi asap cair melalui proses pirolisis diikuti dengan antusias oleh peserta. Peserta memperoleh ilmu pengetahuan tentang cara membuat alat, cara memproduksi asap cair dan manfaat produk bagi pertanian. Selain itu proses produksi asap cair limbah sekam padi bernilai ekonomis. Hal ini dikarenakan bahan produk berasal dari limbah pertanian. Proses produksi 
INTEGRITAS : Jurnal Pengabdian

Vol 5 No 2 Desember 2021

ISSN 2580-7978 (cetak) ISSN 2615-0794 (online)

menggunakan kompor berbahan bakar oli bekas. Oleh karena itu produk asap cair dapat dipasarkan dengan harga terjangkau untuk menambah penghasilan dengan memanfaatkan media sosial.

\section{UCAPAN TERIMA KASIH}

Kami mengucapkan terima kasih kepada pihak-pihak yang berkontribusi pada acara pengabdian masyarakat sehingga acara berlangsung tertib dan lancar, yaitu:

1. Prof. Dr. Ir. H. R. Abdul Haris, M.M selaku Rektor Universitas Panca Marga Probolinggo.

2. Ir. Haryono, M.T selaku Dekan Fakultas Teknik Universitas Panca Marga Probolinggo..

3. Hermanto, SE, MM selaku Ketua Lembaga Penelitian dan Pengabdian Masyarakat (LPPM) Universitas Panca Marga Probolinggo.

4. Rekan-rekan dosen dan mahasiswa di lingkungan Universitas Panca Marga Probolinggo.

\section{DAFTAR PUSTAKA}

Dewi, R. P., Ardhitama, M. B., Mesin, J. T., Teknik, F., \& Tidar, U. (2020). Kajian Potensi Sekam Padi Sebagai Energi Alternatif Pendukung Ketahanan Energi Di Wilayah Magelang. Prosiding Seminar Nasional Riset Teknologi Terapan: 2020, 5.

Ishaq, M., Rumiati, A. T., \& Permatasari, E. O. (2017). Analisis Faktor-Faktor yang Mempengaruhi Produksi Padi di Provinsi Jawa Timur Menggunakan Regresi Semiparametrik Spline. Jurnal Sains Dan Seni ITS, 6(1). https://doi.org/10.12962/j23373520.v6i1.22451

Iskandar, T., \& Kartika Fitri, A. C. (2018). Asap Cair dan Biochar hasil Proses Pyrolisis Sekam Padi dan Biomassa lainnya sebagai Income Generating Unit di Universitas Tribhuwana Tunggadewi. JAST: Jurnal Aplikasi Sains Dan Teknologi, 2(2), 81. https://doi.org/10.33366/jast.v2i2.1109

Istiqomah, I., \& Kusumawati, D. E. (2020). Potensi Asap Cair dari Sekam untuk Meningkatkan Pertumbuhan dan Produksi Padi ( Oryza sativa L.). Buana Sains, 19(2), 23. https://doi.org/10.33366/bs.v19i2.1745

Jaya, J. D., Zulmi, A., Wahyudi, D., Kartika, K., Wati, H., Yuliana, N., \& Kholis, N. (2016). Optimasi Pembuatan Asap Cair Dari Sekam Padi Dan Aplikasinya Sebagai Pupuk Tanaman Hidroponik. Jurnal Teknologi Agro-Industri, 2(2), 28. https://doi.org/10.34128/jtai.v2i2.17

Sari, N. M., Nisa, K., Mahdie, M. F., \& Ulfah, D. (2017). The Utilization of Rice Husk Waste for Mixed Bokashi Fertilizer and Biobriket Making As 
INTEGRITAS : Jurnal Pengabdian

Vol 5 No 2 Desember 2021

ISSN 2580 - 7978 (cetak) ISSN 2615 - 0794 (online)

Biofuels). PengabdianMu, 2(September), 90-97. http: //jurnal.umpalangkaraya.ac.id/ejurnal/pgbmu 